\title{
Retinitis pigmentosa and ocular blood flow
}

\author{
Katarzyna Konieczka ${ }^{1 *}$, Andreas J Flammer ${ }^{2}$, Margarita Todorova', Peter Meyer ${ }^{1}$ and Josef Flammer ${ }^{1}$
}

\begin{abstract}
Is the concept of integrative, preventive and personalised medicine applicable to the relationship between retinitis pigmentosa (RP) and ocular blood flow (OBF)? RP encompasses a group of hereditary diseases of the posterior segment of the eye characterised by degeneration, atrophy and finally loss of photoreceptors and retinal pigment epithelium, leading to progressive visual loss. Many different mutations affecting different genes can lead to the clinical picture of RP. Even though the disease has a clear genetic background, there are obviously other factors influencing the manifestation and progression of RP. In this review, we focus on the role of OBF. There is evidence that, in PR patients, OBF is more reduced than one would expect secondary to the retinal atrophy. The main cause of this additional component seems to be primary vascular dysregulation (PVD) syndrome. As PVD syndrome is partly treatable, a vascular evaluation of RP patients is meaningful. Based on the outcome, a targeted individualised, preventive or supportive treatment might be introduced in selected RP patients.
\end{abstract}

Keywords: Retinitis pigmentosa, Primary vascular dysregulation syndrome, Ocular blood flow, Endothelin, Integrative medicine, Predictive, preventive and personalised medicine

\section{Review}

\section{Introduction}

Retinitis pigmentosa (RP) encompasses a large group of hereditary diseases of the posterior segment of the eye characterised by degeneration, atrophy and finally loss of photoreceptors and retinal pigment epithelium (RPE), leading to progressive visual loss. The term 'retinitis' refers to an inflammatory component. Indeed, most dystrophic and degenerative diseases are accompanied by low-grade inflammation. The term 'pigmentosa' refers to the pigmentary changes with a perivascular 'bonespicule' configuration in the fundus of the eye (Figure 1).

The fact that a number of different mutations affecting different genes [1] lead to the clinical picture described phenomenologically as RP explains the heterogeneity of the phenotypes, including age of onset, rate of progression and severity of the disease. Even though the disease has a genetic background, we assume that additional factors influence the manifestation of the disease. One potential modifying factor is disturbed ocular blood flow (OBF). Indeed, reduced OBF in RP patients has been described [2-4]. Blood flow is more or less always reduced in

\footnotetext{
* Correspondence: kkonieczka@uhbs.ch

${ }^{1}$ Department of Ophthalmology, University of Basel, Mittlere Strasse 91, Basel $\mathrm{CH}-4031$, Switzerland

Full list of author information is available at the end of the article
}

atrophic tissue, secondary to a decreased demand for supply. However, in this review, we summarise and focus on findings indicating an additional primary component of OBF reduction and explore the potential causes of such a primary component. Finally, we discuss the potential benefit of a vascular evaluation of RP patients with regard to prophylactic and supportive treatment in selected patients.

\section{Phenomenology of RP}

As mentioned above, RP refers to a group of diseases of progressive retinal degenerations characterised by loss of photoreceptors and RPE with corresponding loss of function. The disease has a hereditary basis. The prevalence of RP is estimated to be one case among 3,000-5,000 individuals, with a total of about two million affected persons worldwide [5]. The disease starts typically (but not always) with night blindness followed by bilateral, symmetric, progressive concentric constriction of the visual field (Figures 2 and 3), finally leading to tunnel vision or even complete blindness. By fundoscopy, the ophthalmologist finds a bone-spicule retinal pigmentation starting in the periphery and extending slowly towards the centre of the retina, attenuated retinal vessels and, in late stages, a waxy-pale optic nerve head (Figure 4). The electroretinography reveals reduced rod and cone responses 

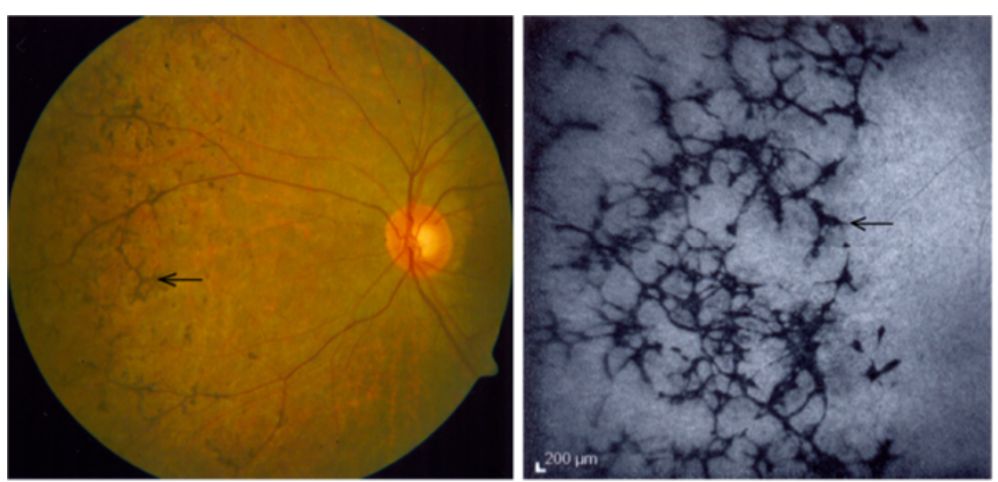

Figure 1 Fundus photograph of a patient with retinitis pigmentosa with the typical bone-spicule pigmentary changes (arrows). Left: photograph; right: fluorescein angiogram.

(Figures 5 and 6), and dark adaptation is reduced and finally lacking (Figure 7).

In addition, RP can be accompanied by cataract [6], open-angle glaucoma, refractive errors [7], keratoconus, optic nerve head drusen and cystoid macular oedema [8] (Figure 8).

It should be noted that both the types and the severity of clinical symptoms and signs, as well as age of onset and rate of progression, vary markedly among patients (reviewed in [9]). Symptoms may already start in childhood; however, they more often begin in early adulthood and sometimes in mid-adulthood. Although the progression of the disease is variable, typically, severe visual impairment occurs most often by the age of about $40-50$ years [1].

This large clinical heterogeneity is at least partly explained by the genetic heterogeneity. However, after a short summary of the genetics of RP, we will focus our discussion here mainly on the question of whether disturbed blood flow may also contribute.

\section{Genetics of RP}

The condition can be inherited in an autosomal-dominant, autosomal-recessive or X-linked fashion. Non-Mendelian inheritance patterns, such as digenic [10] and maternal (mitochondrial) [11] inheritance, have also been reported. For the genetics of RP, we refer to a recently published review [1].

However, the feature shared by all these types of mutations is that they occur in genes coding for proteins involved in vision, either at the level of rods and cones or at that of the pigment epithelium (Figure 9). In the course of the disease, the photoreceptors undergo apoptosis [12], which results in reduced outer nuclear layer thickness of the retina (Figure 10). The pigment deposits, also described as bone-spicule pigmentation, result from both RPE degeneration and RPE migration into the neural retina in response to photoreceptor cells' death [13] (Figure 1).

The exact mechanism of cell death in RP is not yet known. There are indications, however, that oxidative stress is also involved [15]. Any condition that increases or decreases oxidative stress in the retina is therefore of interest.

\section{RP and ocular blood flow}

It is meanwhile well established that OBF in RP patients is reduced not only in the retina [3] and choroid [4], but also in the retroocular vessels [2]. The question arises whether this is only secondary to the retinal atrophy or whether there is a primary component of OBF dysfunction (such as an atrophy-independent reduction of OBF) potentially contributing to the damage. In this context, two questions are important: (1) At what stage of the disease does the onset of OBF reduction occur? (2) Is blood flow reduction confined to the eye?

Interestingly, reduced blood flow velocity in the retina (increase of the arteriovenous passage time) has been observed already in the early stages of RP before the appearance of any ophthalmoscopic signs [16]. With colour Doppler imaging, Cellini et al. also demonstrated reduced peak systolic velocities in both ophthalmic arteries and posterior ciliary arteries (Figure 11) (not explained by the occurrence of other general disorders) [2]. Furthermore, Cellini et al. also demonstrated that blood flow disturbance in RP patients was not confined to the eye, but also occurred in the periphery. With laser Doppler flowmetry, they demonstrated reduced baseline peak flow in the cutaneous capillary of the finger and significantly longer recovery time after cold provocation [2]. Furthermore, these patients had increased endothelin1 (ET-1) plasma levels [2], and ET-1 plasma level correlated with the decrease of peak systolic velocity both in the ophthalmic artery and in the posterior ciliary arteries 


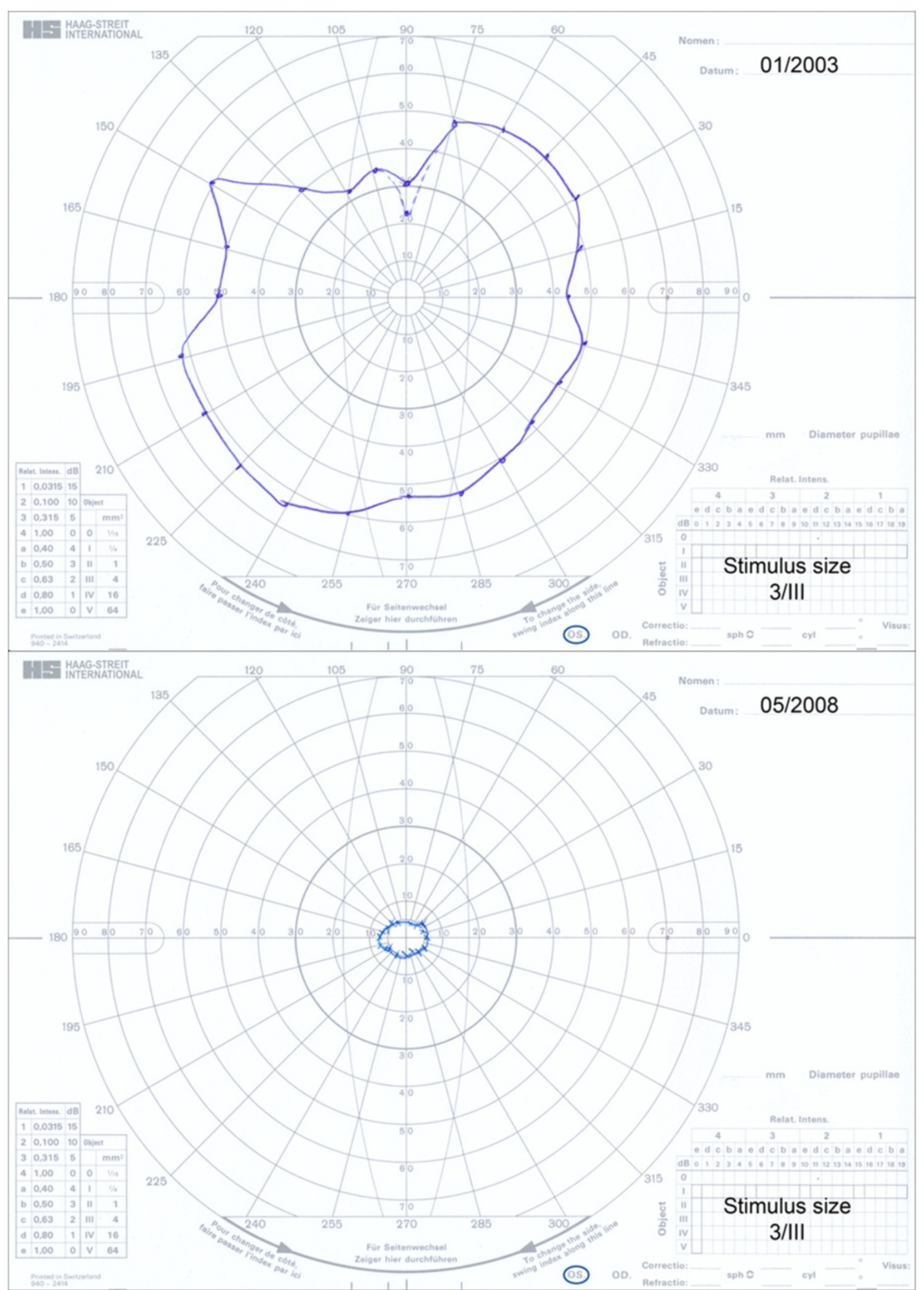

Figure 2 Goldmann visual fields of a RP patient demonstrating progressive concentric constriction. Top: mid-stage RP; bottom: late-stage RP. 

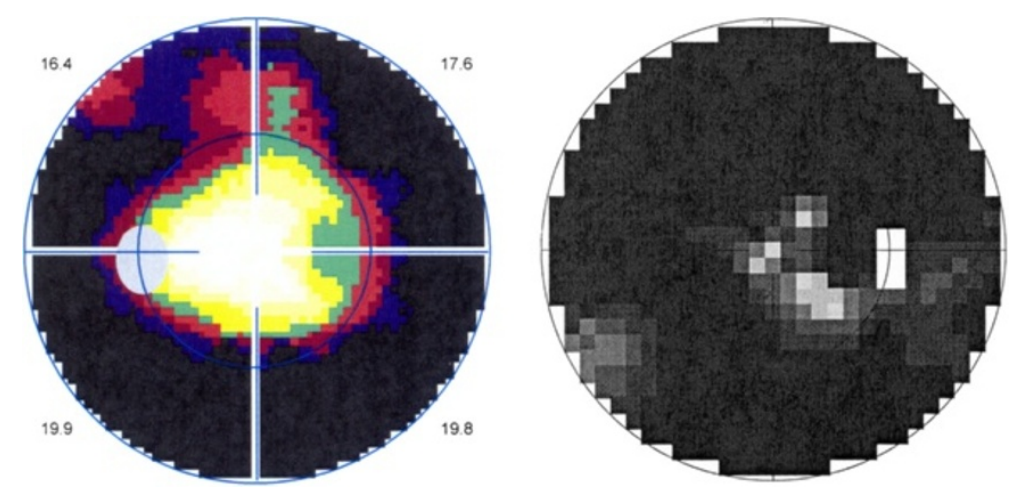

Figure 3 Octopus perimetry demonstrating the extensive visual field loss. Left: mid-stage RP; right: late-stage RP.

[2]. Again, this was observed in RP patients in the early stages of the disease.

Such an increase in ET-1 plasma levels in RP patients has been described repeatedly $[2,17,18]$ but not confirmed by all investigators [19].

It is at present not known why ET-1 levels are increased at least in some RP patients. Endothelin (ET) (Figures 12 and 13), identified in 1988 by Yanagisawa and colleagues [20], is a strong endogenous vasoconstrictor. Endothelins are a family of 21 amino acid peptides, where the predominant isoform is ET-1. ET-1 is essentially produced by vascular endothelial cells. However, more or less, any cell can produce ET-1 if the cell is under stress. Particularly important is hypoxic stress, which leads to an increase of HIF-1 alpha and thereby

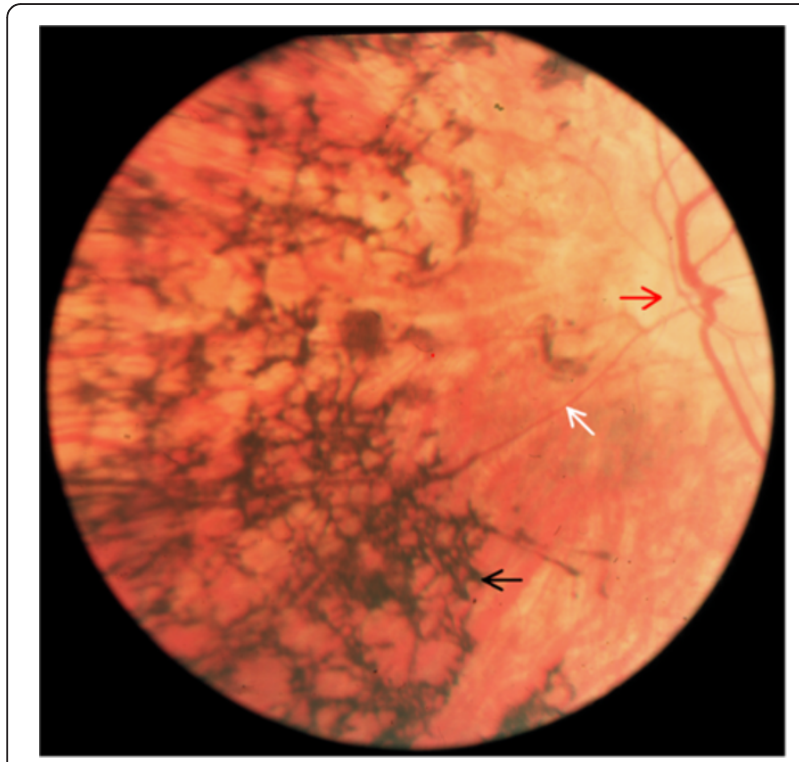

Figure 4 Fundus photograph in patient with late-stage RP with the classic triad. Bone-spicule retinal pigmentation (black arrow), retinal vessel attenuation (white arrow) and waxy disc pallor (red arrow). increased expression of ET-1. Therefore, the observed increase of plasma level could be secondary to hypoxic or oxidative stress somewhere in the body. It is at present unknown whether the ET-1 level in the eye is even more increased than in the plasma. It is known that ET-1 can be synthesised and secreted in RPE cells [21]. This locally secreted ET-1 may also play a role in cell proliferation, migration and repair processes in the retina. Independent of the cause of the ET-1 increase in the plasma, this increase reduces OBF, particularly in the choroid and the optic nerve head [22] and, in high concentrations, even in the retina [23].

\section{The impact of primary vascular dysregulation syndrome in RP}

We hypothesise that primary vascular dysregulation (PVD) syndrome [24-26] might be a main cause for both the observed findings in blood flow reduction and the increase in ET-1.

PVD is a predisposition to react differently to a number of stimuli like coldness $[24,25]$ and physical or emotional stress. The most prominent sign of PVD is the dysregulation of vessels, hence the name of the syndrome [27]. The most notable sign in the vessels are vasospasms. This explains why for PVD the term vasospastic syndrome [28] was used in the past.

The main signs and symptoms of PVD are cold hands and/or feet [25] (Figure 14), particularly when exposed to cold (Figure 15) or emotional stress and low blood pressure [29]. Typically, these subjects have mildly increased ET-1 plasma levels [30]. One cause of the systemic hypotension (Figure 16) observed in these subjects is the reduction of the reabsorption of sodium in the proximal tubule of the kidneys [31]. This, in turn, is due to the increase of prostaglandin E2 (PGE2) by the ET-1. PVD subjects also often have reduced feelings of thirst [30], which is also due to the increased ET-1 plasma levels. 

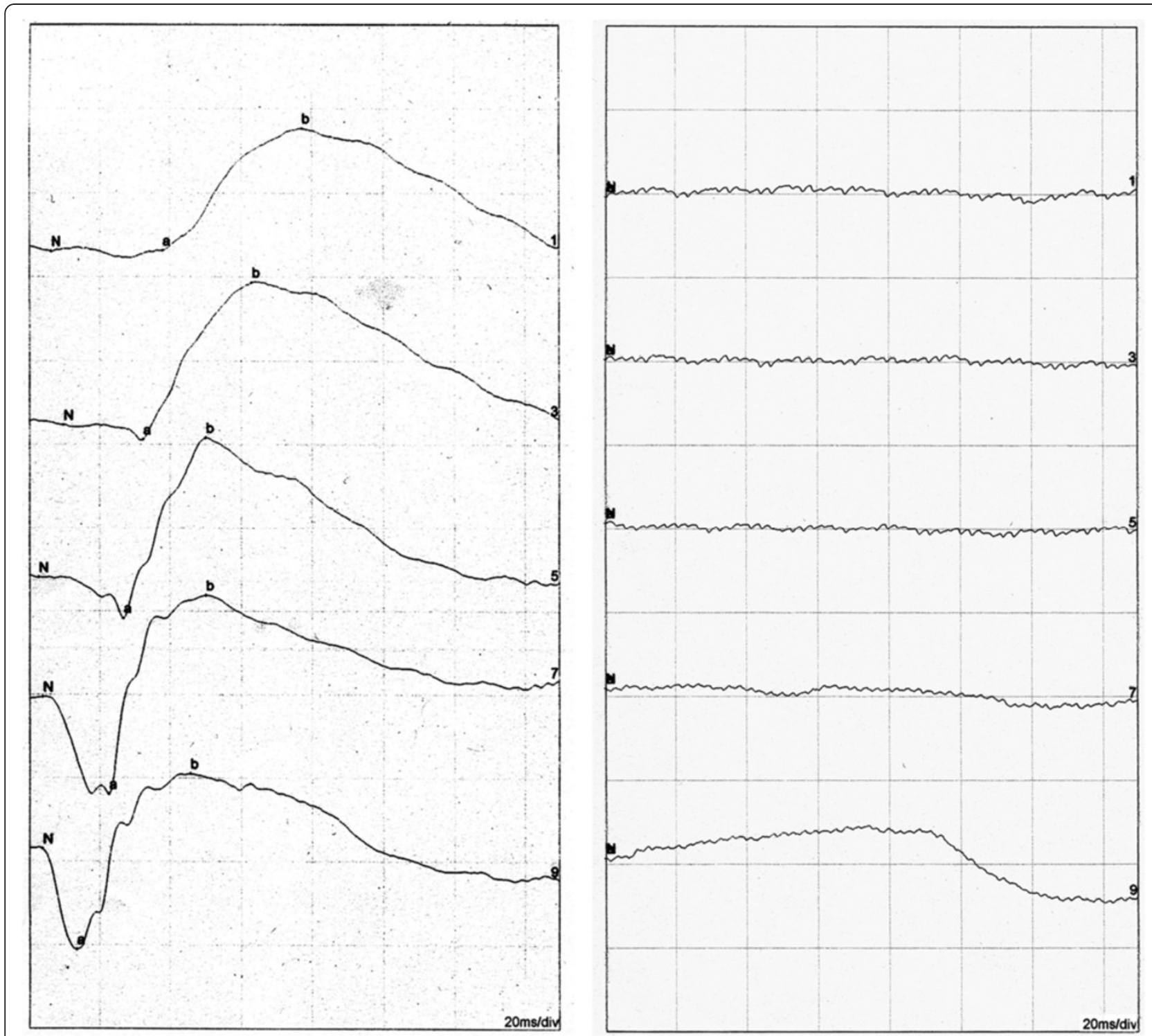

Figure 5 Scotopic electroretinography (ERG), ISCEV standard (International Society for Clinical Electrophysiology of Vision). Normal ERG responses in healthy subject (left) and extinguished responses in RP patient (right).
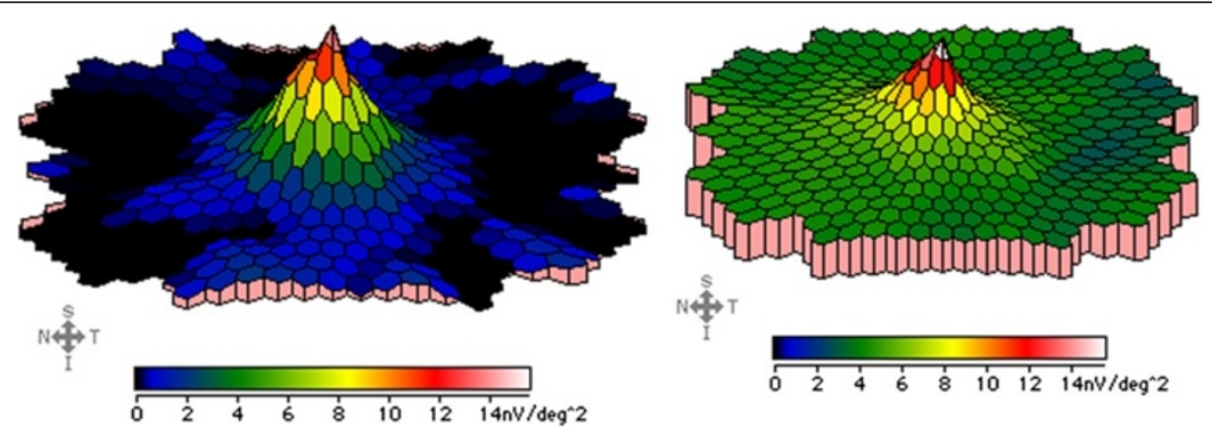

Nit?

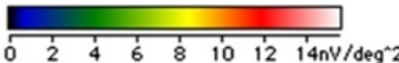

Figure 6 Multifocal electroretinogram. Severely attenuated paracentral responses in RP patient (left) in comparison to normal responses in a healthy subject (right). 

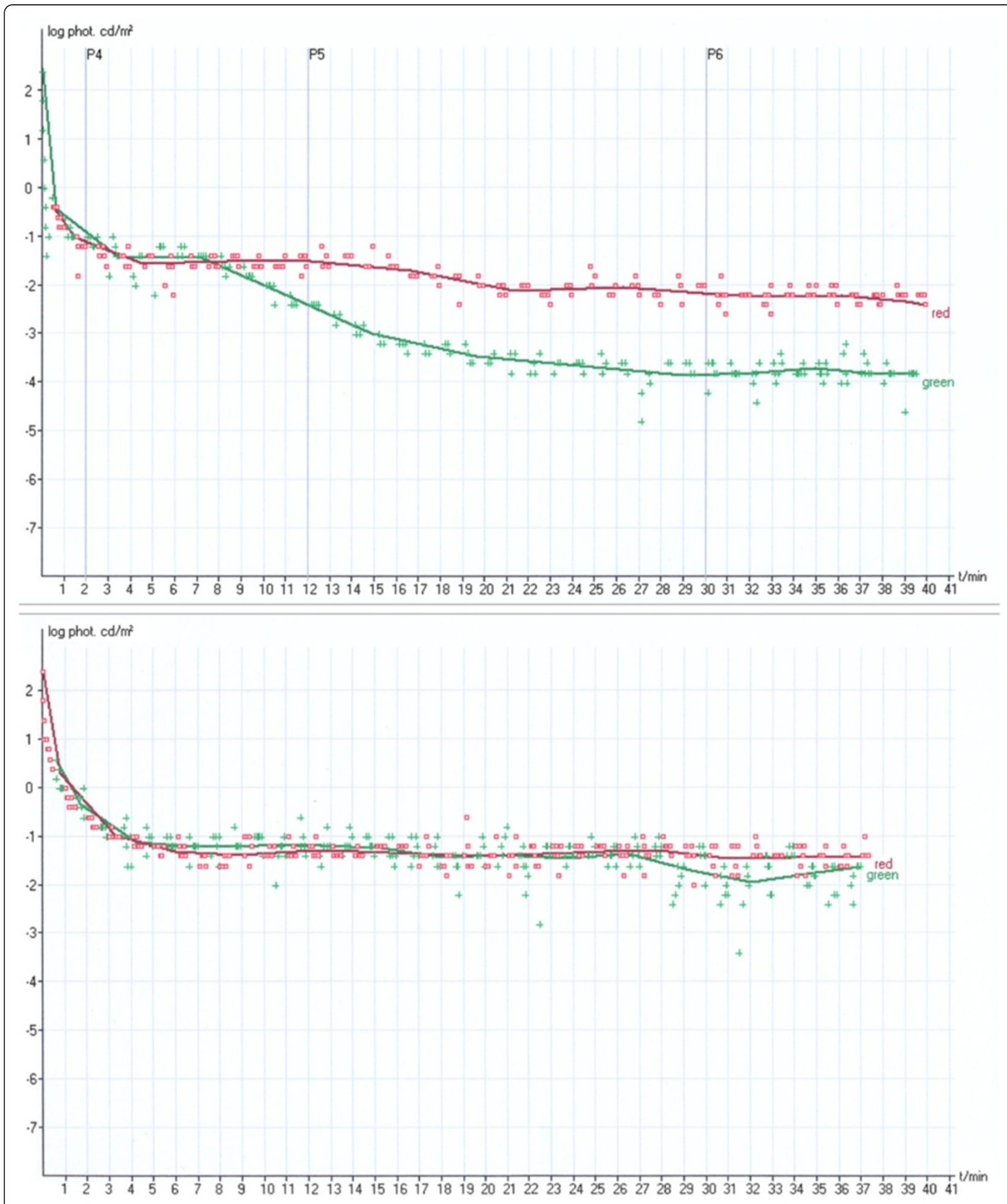

Figure 7 Dark adaptation. Dark adaptation of rods (green line) and cones (red line) in a healthy subject (top) and disturbed dark adaptation (loss of red-green dissociation) in RP patient (bottom).

Furthermore, they respond very sensitively to certain drugs-most probably due to altered expression of $\mathrm{ABC}$ transport proteins [33]. PVD subjects also require a longer time to fall asleep, especially when they are cold [34] (as warm feet are generally a prerequisite for falling asleep). They also suffer more often from headaches and 

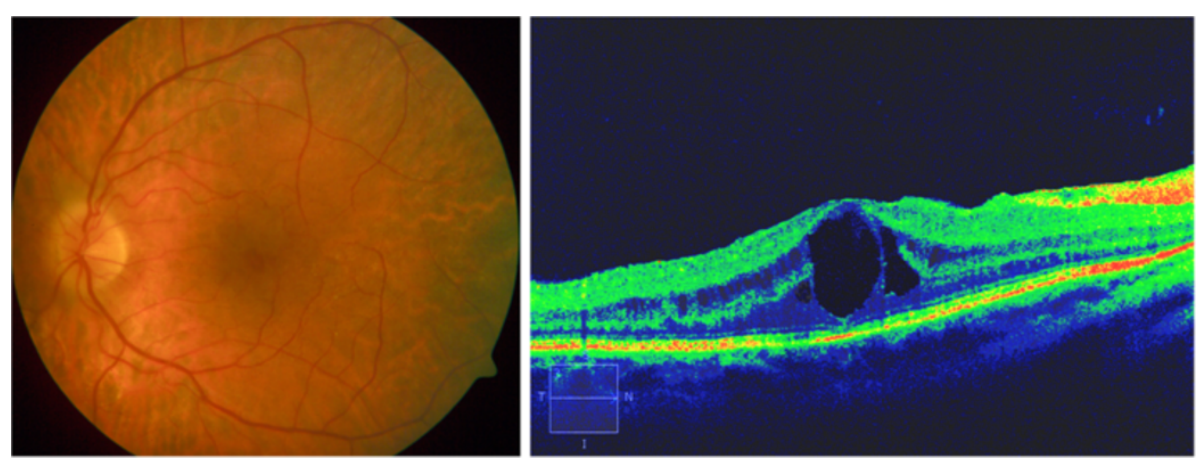

Figure 8 Cystoid macular oedema in RP patient. Left: fundus photograph; right: optical coherence tomography image.

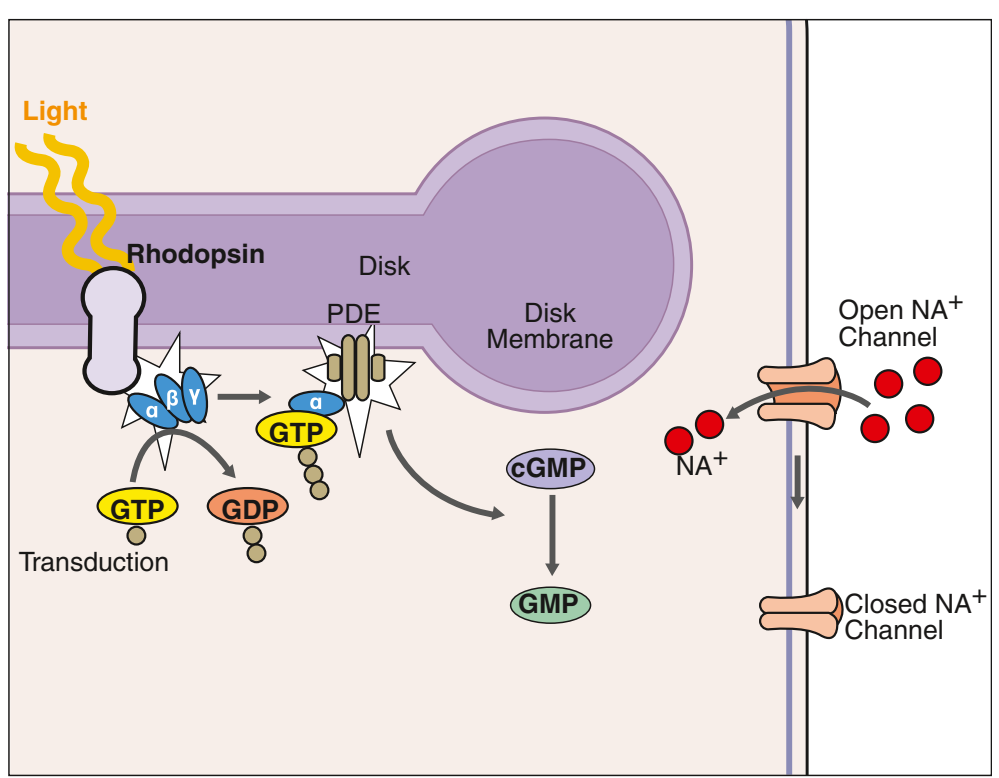

Figure 9 Phototransduction in rod photoreceptors. Mutations of genes involved in this process can lead to RP (Adapted from [14] with permission).

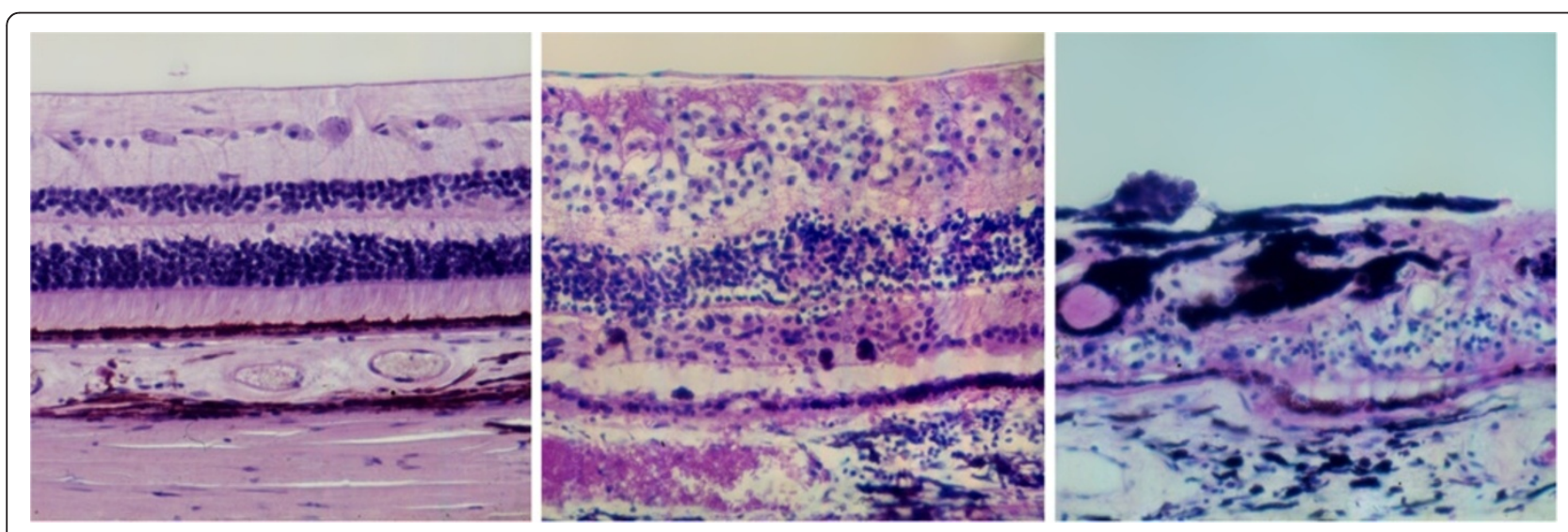

Figure 10 Histological section through the human retina. Left: healthy retina; middle: retina of a patient with mid-stage RP; right: retina of a patient with late-stage RP. 


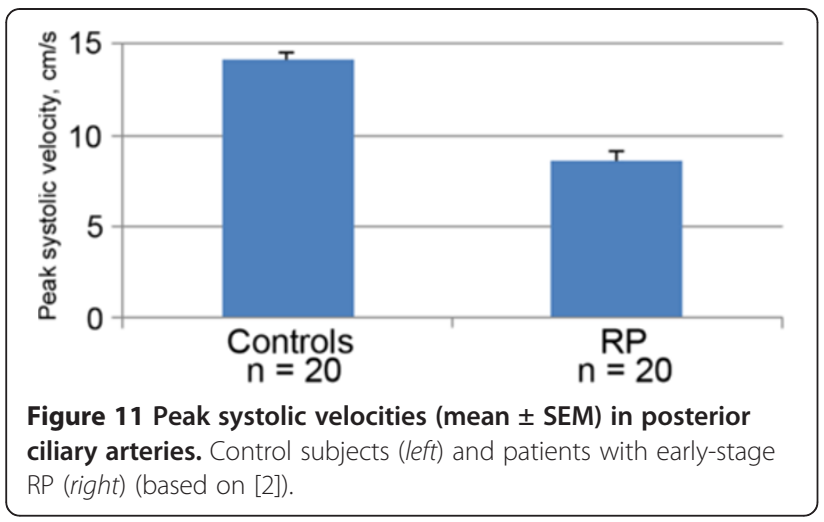

migraines [35] and have increased pain sensation [36] (ET level influences the threshold of pain sensation). PVD occurs more often in females [37] and in thin subjects [37-39].

Interestingly, most of these signs and symptoms typical of PVD subjects also seem to occur more frequently in RP patients than in unselected controls (Konieczka K et al., unpublished work). We therefore discuss here the link between PVD and OBF. PVD syndrome also includes disturbed autoregulation of ocular perfusion [40], spatial irregularity of retinal vessels and reduced neurovascular coupling [41] (Figure 17). Disturbed regulation of OBF leads to unstable blood flow (and therefore unstable blood supply), and this, in turn, leads to an increase in free radicals and chronic oxidative stress. Indeed, there are many indications that oxidative stress is increased in PVD [42].
The high prevalence of PVD in RP patients might explain the primary component of OBF dysfunction in RP patients.

\section{Therapeutic consequences}

Dealing with a severe disease, any treatment ameliorating this condition would be welcome. On the other hand, it would be wise to avoid encouraging false hope. We know from clinical experience that the symptoms of PVD can be reduced to some extent. If blood pressure is very low, increased salt intake increases blood pressure slightly but improves vascular regulation markedly. The same observation has been made with fludrocortisone [43]. The other symptoms of dysregulation can be mitigated either by magnesium [44] or by a low dose of calcium channel blockers (CCBs) [45] or even omega-3 fatty acids $[46,47]$.

Interestingly, it has been shown that central visual field defects progress slower in RP patients treated with the CCB nilvadipine [48]. Furthermore, in a patient with the clinical picture of RP, without a genetic history but with chronic hypomagnesaemia, the visual field progression was stopped after magnesium (a physiological CCB) substitution [49]. Magnesium and CCBs both have some neuroprotective effect and improve blood flow regulation. They reduce the vasoconstrictive effect of ET-1 $[50,51]$.

Interestingly, diet rich in omega-3 fatty acids-which we often use to treat PVD-can also slow mean annual rates of decline of visual acuity in RP patients receiving vitamin A [52]. Furthermore, antioxidants (used to treat

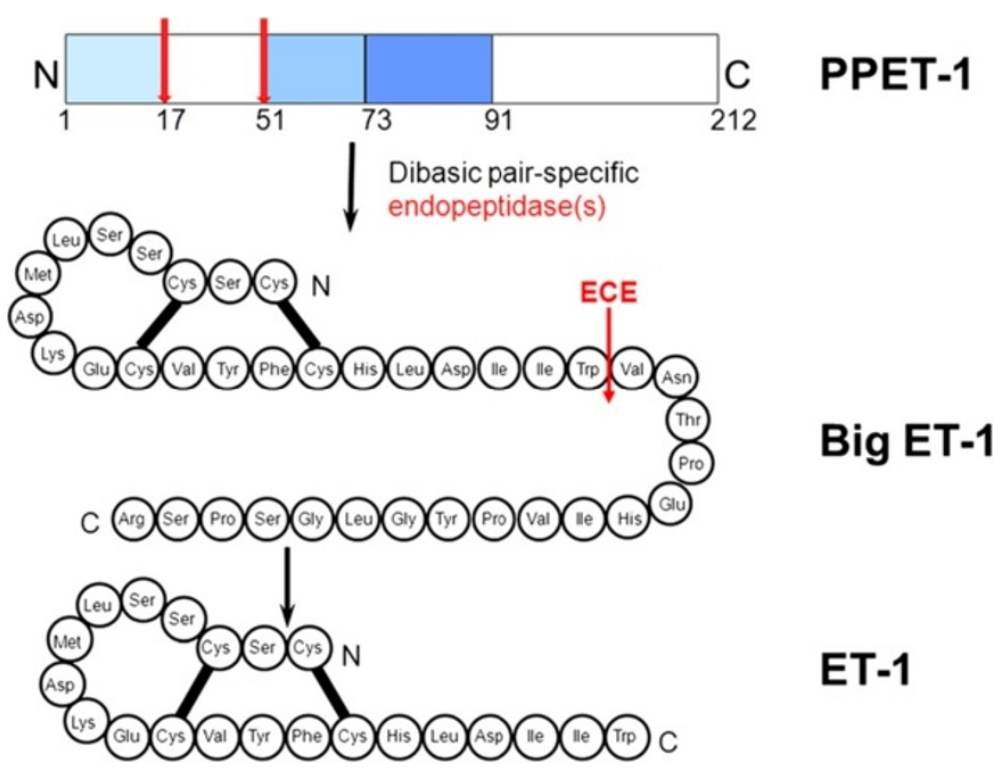

Figure 12 Endothelin. ET-1 arises by cleaving the precursor molecules (Adapted from [14] with permission). 


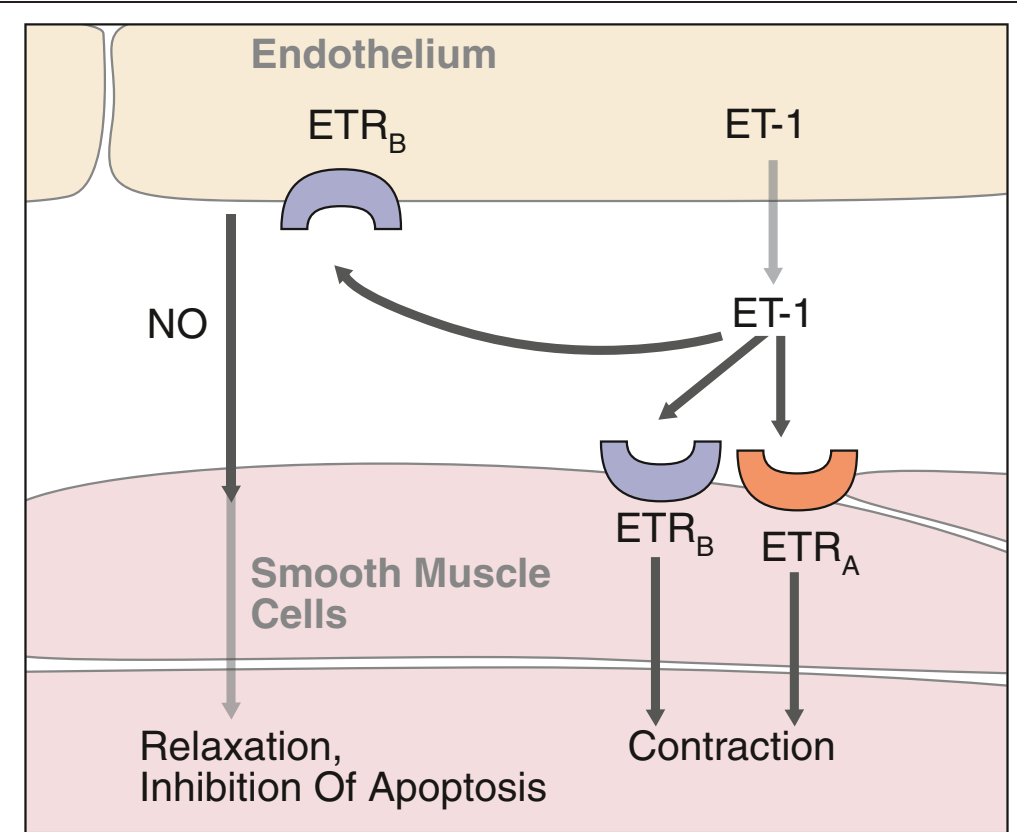

Figure 13 Endothelin receptors. In humans, the effects of ET-1 are mediated by two types of ET receptors: the type-A receptor $\left(E T_{A}\right)$ and the type-B receptor ( $\mathrm{ET}_{\mathrm{B}}$ ) (Adapted from [14] with permission).

PVD subjects) may also be helpful for RP patients. Indeed, oxidative damage is under investigation as a possible therapeutic target in RP disease [15,53].

As OBF dysfunction, potentially due to PVD syndrome, occurs often in RP patients, we consider the vascular evaluation of such patients meaningful. If reduced OBF in the context of PVD syndrome is diagnosed, a supportive treatment with a diet rich in both omega-3 fatty acids and antioxidants and with magnesium (or, in selected patients, even with low-dose CCBs)
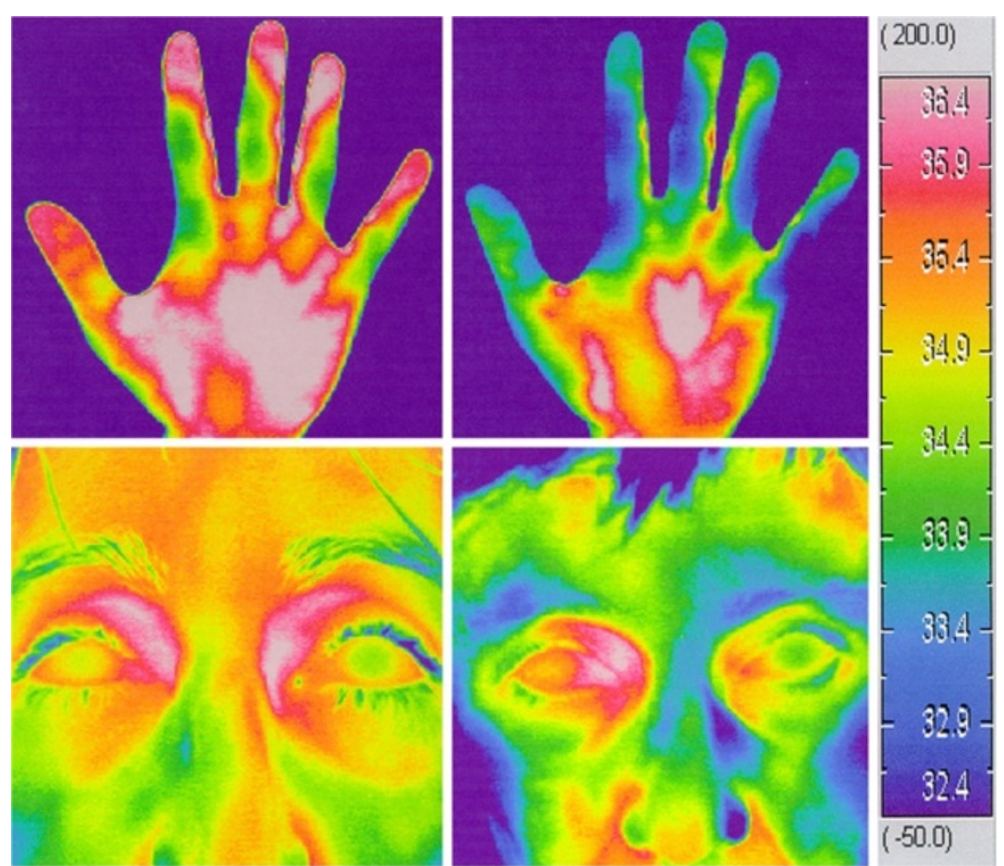

Figure 14 Thermography of hands and faces. A subject without PVD (left) and a subject with PVD (right) (Adapted from [32] with permission). 

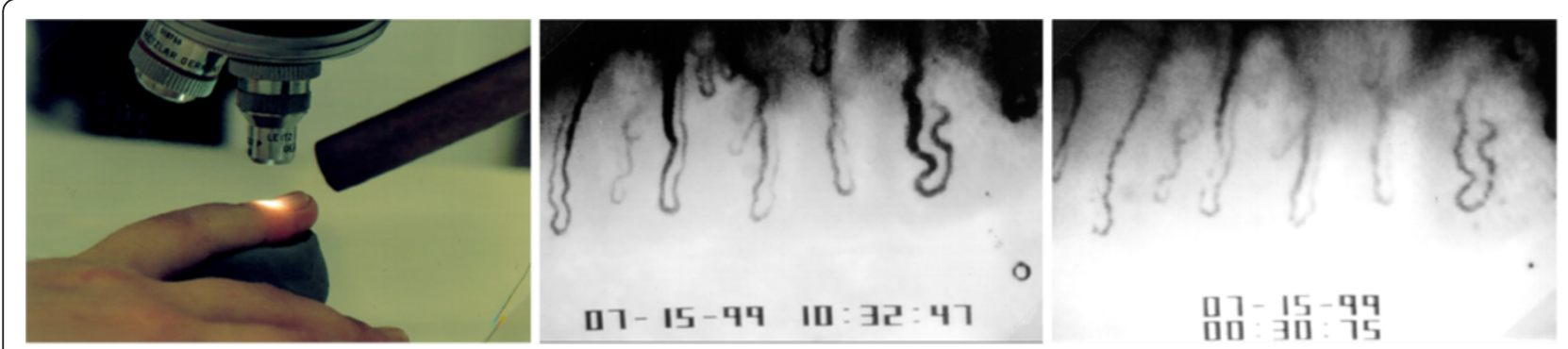

Figure 15 The nailfold capillary microscopy examination. Left: examination setting with cooling device; middle: picture from a video with normal capillary blood flow; right: picture from the video demonstrating blood flow cessation after cold provocation in a PVD subject (Adapted from [32] with permission).

might be helpful. If blood pressure is very low, increased salt intake or, in extreme cases, even low-dose fludrocortisone might be worthwhile. We would like to emphasise, however, that such recommendations are mainly based on clinical experience. Scientific studies are unfortunately, at present, still sparse.

\section{Conclusions}

RP is a disease with a clear genetic background. However, OBF is more reduced in RP than one would expect secondary to the retinal atrophy. The main cause of this OBF reduction seems to be PVD syndrome. As PVD syndrome is partly treatable, an individualised treatment [54,55] might be introduced in selected RP patients based on the outcome of a vascular evaluation.

Further studies are recommended to establish the relationship between reduced OBF and the different stages of the RP disease and to confirm our hypothesis that the main cause of this blood flow reduction is the PVD syndrome. Furthermore, a more detailed relationship between the vascular dysfunction and other involved factors such as ET or nitric oxide should be established.
Controlled studies evaluating the effect of vascular treatment on visual function will be crucial. While waiting for the outcomes of such studies, we recommend simple, not expensive treatments such as magnesium or omega3 fatty acids in targeted selective patients [54,55].

\section{Abbreviations}

CCB: Calcium channel blocker; ET: Endothelin; ET-1: Endothelin-1; OBF: Ocular blood flow; PVD: Primary vascular dysregulation; RP: Retinitis pigmentosa; RPE: Retinal pigment epithelium.

\section{Competing interests}

The authors declare that they have no competing interests.

\section{Authors' contributions}

All authors have contributed to the manuscript. All authors read and approved the final manuscript.

\section{Acknowledgements}

We would like to acknowledge the great support of Mrs. C. Fasser and Mr. S. Huesler-Lichtsteiner from Swiss RP Association, Zurich, Switzerland. Mrs. Daniela Hauenstein is also acknowledged for preparing the figures.

\section{Author details}

'Department of Ophthalmology, University of Basel, Mittlere Strasse 91, Basel $\mathrm{CH}-4031$, Switzerland. ${ }^{2}$ Cardiovascular Center, Cardiology, University Hospital Zurich, Zurich $\mathrm{CH}-8091$, Switzerland.

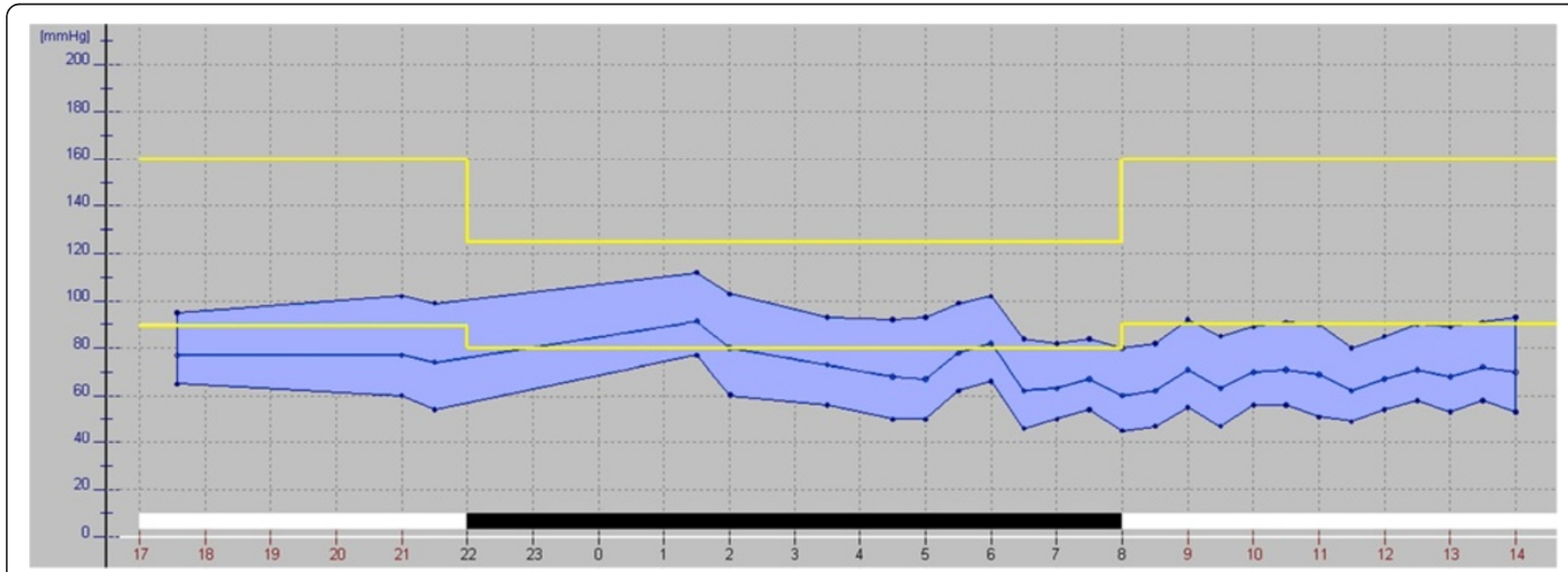

Figure 16 Outcome of blood pressure monitoring. Yellow: normal range; blue: systolic, diastolic and mean blood pressure of a RP patient. 
Konieczka et al. The EPMA Journal 2012, 3:17

Page 11 of 13

http://www.epmajournal.com/content/3/1/17
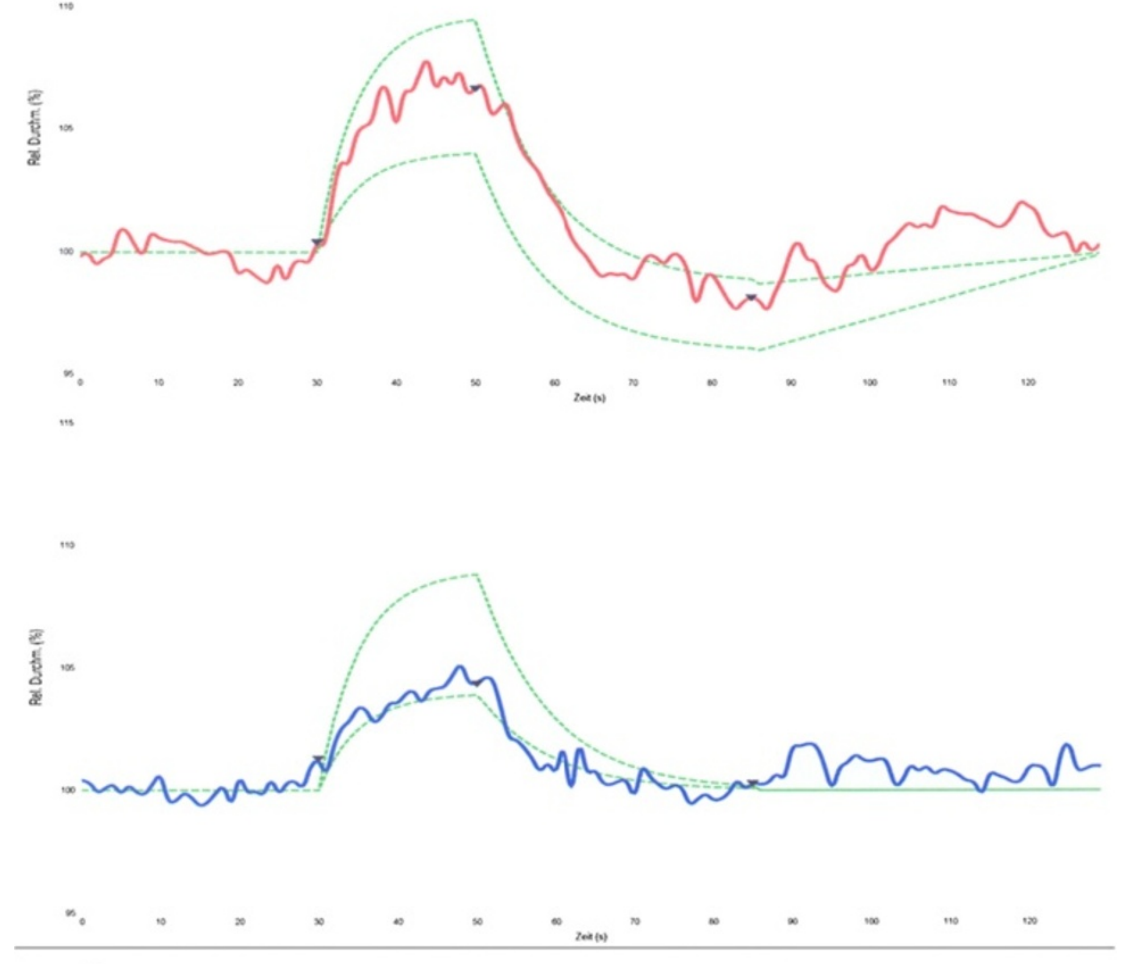

115

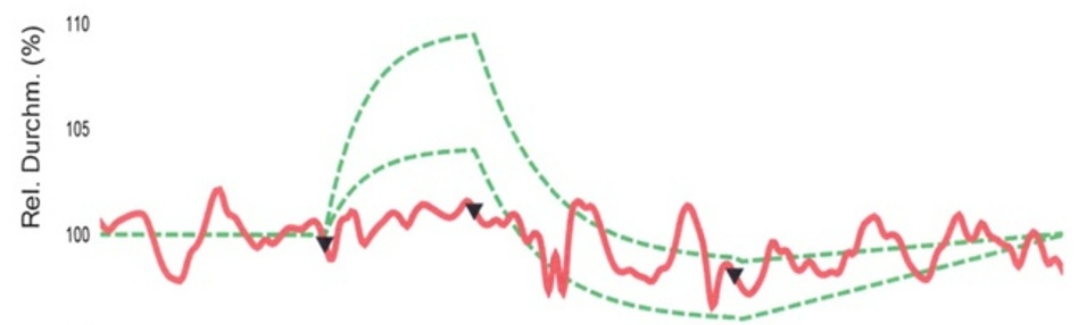

${ }^{95}$

$\begin{array}{llll}10 & 20 & 30 & 40\end{array}$

50

6)

$110 \quad 120$

115
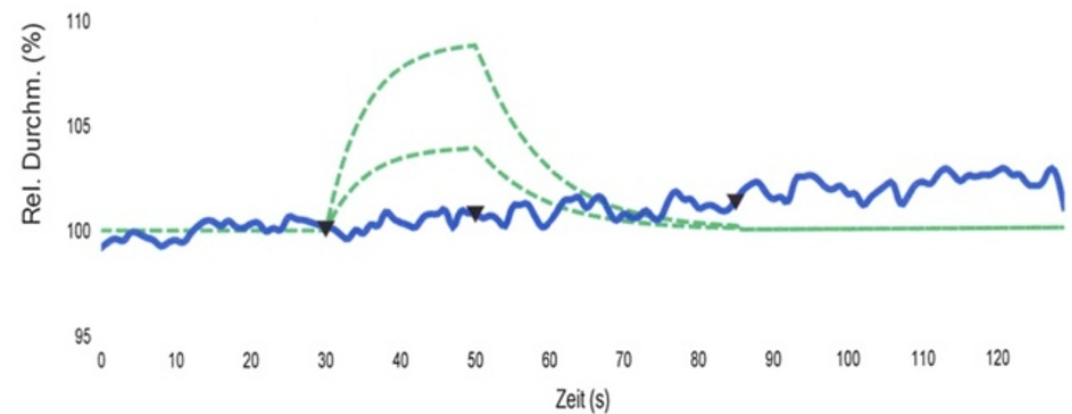

Figure 17 Vascular response to light measured with a Retinal Vessel Analyser. Top: normal responses of both arteries and veins; bottom: reduced responses of both arteries and veins in a RP patient. Red lines: arteries; blue lines: veins. 
Received: 8 October 2012 Accepted: 12 November 2012

Published: 3 December 2012

\section{References}

1. Ferrari S, Di lorio E, Barbaro V, Ponzin D, Sorrentino FS, Parmeggiani F: Retinitis pigmentosa: genes and disease mechanisms. Curr Genomics 2011, 12:238-249.

2. Cellini M, Strobbe E, Gizzi C, Campos EC: ET-1 plasma levels and ocular blood flow in retinitis pigmentosa. Can J Physiol Pharmacol 2010, 88:630-635.

3. Grunwald JE, Maguire AM, Dupont J: Retinal hemodynamics in retinitis pigmentosa. Am J Ophthalmol 1996, 122:502-508.

4. Falsini B, Anselmi GM, Marangoni D, D'Esposito F, Fadda A, Di Renzo A Campos EC, Riva CE: Subfoveal choroidal blood flow and central retinal function in retinitis pigmentosa. Invest Ophthalmol Vis Sci 2011 52:1064-1069

5. Chizzolini M, Galan A, Milan E, Sebastiani A, Costagliola C, Parmeggiani F: Good epidemiologic practice in retinitis pigmentosa: from phenotyping to biobanking. Curr Genomics 2011, 12:260-266.

6. Heckenlively J: The frequency of posterior subcapsular cataract in the hereditary retinal degenerations. Am J Ophthalmol 1982, 93:733-738.

7. Sieving PA, Fishman GA: Refractive errors of retinitis pigmentosa patients. Br J Ophthalmol 1978, 62:163-167.

8. Fishman GA, Maggiano JM, Fishman M: Foveal lesions seen in retinitis pigmentosa. Arch Ophthalmol 1977, 95:1993-1996.

9. Hamel C: Retinitis pigmentosa. Orphanet J Rare Dis 2006, 1:40.

10. Kajiwara K, Berson EL, Dryja TP: Digenic retinitis pigmentosa due to mutations at the unlinked peripherin/RDS and ROM1 loci. Science 1994 264:1604-1608.

11. Mansergh FC, Millington-Ward S, Kennan A, Kiang AS, Humphries M, Farrar GJ, Humphries P, Kenna PF: Retinitis pigmentosa and progressive sensorineural hearing loss caused by a C12258A mutation in the mitochondrial MTTS2 gene. Am J Hum Genet 1999, 64:971-985.

12. Marigo V: Programmed cell death in retinal degeneration: targeting apoptosis in photoreceptors as potential therapy for retinal degeneration. Cell Cycle 2007, 6:652-655.

13. Li ZY, Possin DE, Milam AH: Histopathology of bone spicule pigmentation in retinitis pigmentosa. Ophthalmology 1995, 102:805-816.

14. Flammer J, Mozaffarieh M, Bebie H: Basic Sciences in Ophthalmology: Physics and Chemistry. Heidelberg: Springer; in press.

15. Komeima K, Rogers BS, Campochiaro PA: Antioxidants slow photoreceptor cell death in mouse models of retinitis pigmentosa. J Cell Physiol 2007 213:809-815.

16. Wolf S, Pöstgens H, Bertram B, Schulte K, Teping C, Reim M: Hemodynamic findings in patients with retinitis pigmentosa. Klin Monbl Augenheilkd 1991, 199:325-329.

17. Cellini M, Santiago L, Versura P, Caramazza R: Plasma levels of endothelin-1 in retinitis pigmentosa. Ophthalmologica 2002, 216:265-268.

18. Vingolo EM, Lupo S, Grenga PL, Salvatore S, Zinnamosca L, Cotesta D, Petramala L, Letizia C: Endothelin-1 plasma concentrations in patients with retinitis pigmentosa. Regul Pept 2010, 160:64-67.

19. Ohguro H, Mashima $Y$, Nakazawa M: Low levels of plasma endothelin-1 in patients with retinitis pigmentosa. Clin Ophthalmol 2010, 4:569-573.

20. Yanagisawa M, Kurihara H, Kimura S, Tomobe $Y$, Kobayashi M, Mitsui $Y$, Yazaki Y, Goto K, Masaki T: A novel potent vasoconstrictor peptide produced by vascular endothelial cells. Nature 1988, 332:411-415.

21. Narayan S, Prasanna G, Krishnamoorthy RR, Zhang X, Yorio T: Endothelin-1 synthesis and secretion in human retinal pigment epithelial cells (ARPE-19): differential regulation by cholinergics and TNF-alpha. Invest Ophthalmol Vis Sci 2003, 44:4885-4894.

22. Polak K, Petternel V, Luksch A, Krohn J, Findl O, Polska E, Schmetterer L: Effect of endothelin and BQ123 on ocular blood flow parameters in healthy subjects. Invest Ophthalmol Vis Sci 2001, 42:2949-2956.

23. Polak K, Luksch A, Frank B, Jandrasits K, Polska E, Schmetterer L: Regulation of human retinal blood flow by endothelin-1. Exp Eye Res 2003, 76:633-640.

24. Saner H, Würbel H, Mahler F, Flammer J, Gasser P: Microvasculatory evaluation of vasospastic syndromes. Adv Exp Med Biol 1987, 220:215-218.
25. Guthauser U, Flammer J, Mahler F: The relationship between digital and ocular vasospasm. Graefes Arch Clin Exp Ophthalmol 1988, 226:224-226.

26. Flammer J, Mozaffarieh M: Autoregulation, a balancing act between supply and demand. Can J Ophthalmol 2008, 43:317-321.

27. Flammer J: The concept of vascular dysregulation in glaucoma. In Nitric Oxide and Endothelin in the Pathogenesis of Glaucoma. Edited by Haefliger IO, Flammer J. Philadelphia: Lippincott-Raven; 1998:14-21.

28. Mahler F, Saner H, Würbel H, Flammer J: Local cooling test for clinical capillaroscopy in Raynaud's phenomenon, unstable angina, and vasospastic visual disorders. Vasa 1989, 18:201-204

29. Gherghel D, Orgül S, Gugleta K, Flammer J: Retrobulbar blood flow in glaucoma patients with nocturnal over-dipping in systemic blood pressure. Am J Ophthalmol 2001, 132:641-647.

30. Teuchner B, Orgül S, Ulmer H, Haufschild T, Flammer J: Reduced thirst in patients with a vasospastic syndrome. Acta Ophthalmol Scand 2004, 82:738-740

31. Pechere-Bertschi A, Sunaric-Megevand G, Haefliger I, Panarello F, Maillard M, Burnier M: Renal sodium handling in patients with normal pressure glaucoma. Clin Sci 2007, 112:337-344.

32. Flammer J: Glaucoma. Bern: Hogrefe \& Huber; 2006.

33. Wunderlich K, Zimmerman C, Gutmann H, Teuchner B, Flammer J, Drewe J: Vasospastic persons exhibit differential expression of $A B C$-transport proteins. Mol Vis 2003, 9:756-761

34. Pache M, Kräuchi K, Cajochen C, Wirz-Justice A, Dubler B, Flammer J, Kaiser $\mathrm{HJ}$ : Cold feet and prolonged sleep-onset latency in vasospastic syndrome. Lancet 2001, 358:125-126.

35. Gasser P, Meienberg O: Finger microcirculation in classical migraine. A video-microscopic study of nailfold capillaries. Eur Neurol 1991, 31:168-171

36. Pache M, Ochs J, Genth E, Mierau R, Kube T, Flammer J: Increased plasma endothelin-1 levels in fibromyalgia syndrome. Rheumatology 2003 42:493-494

37. Mozaffarieh M, Fontana Gasio P, Schötzau A, Orgül S, Flammer J, Kräuchi K Thermal discomfort with cold extremities in relation to age, gender and body mass index in a random sample of a Swiss urban population. Popul Health Metr 2010, 8:17.

38. Kavroulaki D, Gugleta K, Kochkorov A, Katamay R, Flammer J, Orgül S: Relation of body mass index and blood pressure to subjective and objective acral temperature. Klin Monbl Augenheilkd 2009, 226:328-331.

39. Gasser P, Stümpfig D, Schötzau A, Ackermann-Liebrich U, Flammer J: Body mass index in glaucoma. J Glaucoma 1999, 8:8-11.

40. Emre M, Orgül S, Gugleta K, Flammer J: Ocular blood flow alteration in glaucoma is related to systemic vascular dysregulation. $\mathrm{Br} J$ Ophthalmol 2004, 88:662-666.

41. Gugleta K, Zawinka C, Rickenbacher I, Kochkorov A, Katamay R, Flammer J, Orgul S: Analysis of retinal vasodilation after flicker light stimulation in relation to vasospastic propensity. Invest Ophthalmol Vis Sci 2006, 47:4034-4041

42. Mozaffarieh M, Schoetzau A, Sauter M, Grieshaber M, Orgül S, Golubnitschaja O, Flammer J: Comet assay analysis of single-stranded DNA breaks in circulating leukocytes of glaucoma patients. Mol Vis 2008 , 14:1584-1588.

43. Gugleta K, Orgül S, Stümpfig D, Dubler B, Flammer J: Fludrocortisone in the treatment of systemic hypotension in primary open-angle glaucoma patients. Int Ophthalmol 1999, 23:25-30.

44. Gaspar AZ, Gasser P, Flammer J: The influence of magnesium on visual field and peripheral vasospasm in glaucoma. Ophthalmologica 1995, 209:11-13.

45. Strenn K, Matulla B, Wolzt M, Findl O, Bekes MC, Lamsfuss U, Graselli U, Rainer G, Menapace R, Eichler HG, Schmetterer L: Reversal of endothelin-1induced ocular hemodynamic effects by low-dose nifedipine in humans. Clin Pharmacol Ther 1998, 63:54-63.

46. Nyby MD, Hori MT, Ormsby B, Gabrielian A, Tuck ML: Eicosapentaenoic acid inhibits $\mathrm{Ca} 2+$ mobilization and PKC activity in vascular smooth muscle cells. Am J Hypertens 2003, 16:708-714.

47. Shirao S, Fujisawa H, Kudo A, Kurokawa T, Yoneda H, Kunitsugu I, Ogasawara K, Soma M, Kobayashi S, Ogawa A, Suzuki M: Inhibitory effects of eicosapentaenoic acid on chronic cerebral vasospasm after subarachnoid hemorrhage: possible involvement of a 
sphingosylphosphorylcholine-rho-kinase pathway. Cerebrovasc Dis 2008, 26:30-37.

48. Nakazawa M, Ohguro H, Takeuchi K, Miyagawa Y, Ito T, Metoki T: Effect of nilvadipine on central visual field in retinitis pigmentosa: a 30-month clinical trial. Ophthalmologica 2011, 225:120-126.

49. Liang SY, Lee LR: Retinitis pigmentosa associated with hypomagnesaemia. Clin Experiment Ophthalmol 2010, 38:645-647.

50. Meyer P, Lang MG, Flammer J, Lüscher TF: Effects of calcium channel blockers on the response to endothelin-1, bradykinin and sodium nitroprusside in porcine ciliary arteries. Exp Eye Res 1995, 60:505-510

51. Dettmann ES, Lüscher TF, Flammer J, Haefliger IO: Modulation of endothelin-1-induced contractions by magnesium/calcium in porcine ciliary arteries. Graefes Arch Clin Exp Ophthalmol 1998, 236:47-51.

52. Berson EL, Rosner B, Sandberg MA, Weigel-Difranco C, Willett WC: $\omega-3$ intake and visual acuity in patients with retinitis pigmentosa receiving vitamin A. Arch Ophthalmol 2012, 130:707-711.

53. Komeima K, Rogers BS, Lu L, Campochiaro PA: Antioxidants reduce cone cell death in a model of retinitis pigmentosa. Proc Natl Acad Sci USA 2006, 103:11300-11305.

54. Golubnitschaja O, Costigliola V, EPMA: General Report \& Recommendations in Predictive, Preventive and Personalised Medicine 2012: White Paper of the European Association for Predictive, Preventive and Personalised Medicine. EPMA J 2012, 3:14.

55. Golubnitschaja O: Neurodegeneration: accelerated ageing or inadequate healthcare? EPMA J 2010, 1:211-215.

doi:10.1186/1878-5085-3-17

Cite this article as: Konieczka et al:: Retinitis pigmentosa and ocular blood flow. The EPMA Journal 2012 3:17.

\section{Submit your next manuscript to BioMed Central and take full advantage of:}

- Convenient online submission

- Thorough peer review

- No space constraints or color figure charges

- Immediate publication on acceptance

- Inclusion in PubMed, CAS, Scopus and Google Scholar

- Research which is freely available for redistribution 